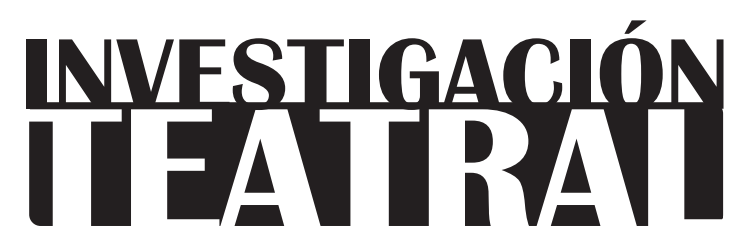

Revista de artes escénicas y performatividad

Vol. 10, Núm. 16

octubre 2019-marzo 2020

Segunda época

ISSN impreso: 1665-8728

ISSN electrónico: 2594-0953

Universidad Veracruzana

\title{
Xalapa, capital teatral de México
}

\author{
Alejandra Serrano Rodríguez*
}
* Centro Nacional de Investigación, Documentación e Información Teatral "Rodolfo Usigli", México.
e-mail: as.teatromexicano@gmail.com

Recibido: 31 de marzo de 2019

Aceptado: 12 de junio de 2019

Doi: $10.25009 /$ it.v10i16.2605 


\title{
Xalapa, capital teatral de México
}

\section{Resumen}

Este artículo tiene como finalidad demostrar que Xalapa es la ciudad con mayor actividad teatral en el país. Para esto se proporcionará una definición de actividad teatral basada en un análisis documental. La importancia de señalar un foco cultural fuera de la Ciudad de México es relevante en términos de diversidad cultural y descentralización de la cultura.

Palabras clave: teatro, documentación, descentralización, espacios independientes, Xalapa, Veracruz.

\section{Xalapa: Mexico's Theatre Capital}

\begin{abstract}
Based on a documentary analysis, this article seeks to position Xalapa as the city with the largest theatrical activity in the country. The presence of a cultural core outside Mexico City is relevant in terms of both cultural diversity and cultural decentralization.
\end{abstract}

Keywords: theatre, documentation, decentralization, independent theater spaces, Xalapa, Veracruz. 


\title{
Xalapa, capital teatral de México
}

\section{Introducción}

\footnotetext{
partir de estudiar un caso específico, como la actividad teatral en Xalapa -la capital del estado mexicano de Veracruz-, podemos establecer puentes para discutir
problemas más generales que enfrenta el país. Se trata de un intento por configurar una historia cultural contemporánea al modo en que Pilar Gonzalbo lo refiere:
}

\begin{abstract}
Más que las obras de arte en sí mismas a nosotros nos importa su recepción en cada momento histórico y para cada sujeto social [...] La recepción es entonces tan determinante como la obra misma y la cultura está constituida no solamente por las creaciones maravillosas de algunos hombres sino también por los comportamientos cotidianos (“La historia cultural” 21).
\end{abstract}

De este modo, es importante revisar la relación de la ciudad con el teatro. Conocer las características específicas de la actividad teatral en cada estado del país puede otorgar información para desarrollar políticas culturales y programas adecuados para fortalecer los puntos débiles y promover sus fortalezas. Compartir información e identificar tendencias y desafíos del teatro en México fuera de la capital es crucial para promover una diversidad cultural en justa participación. 


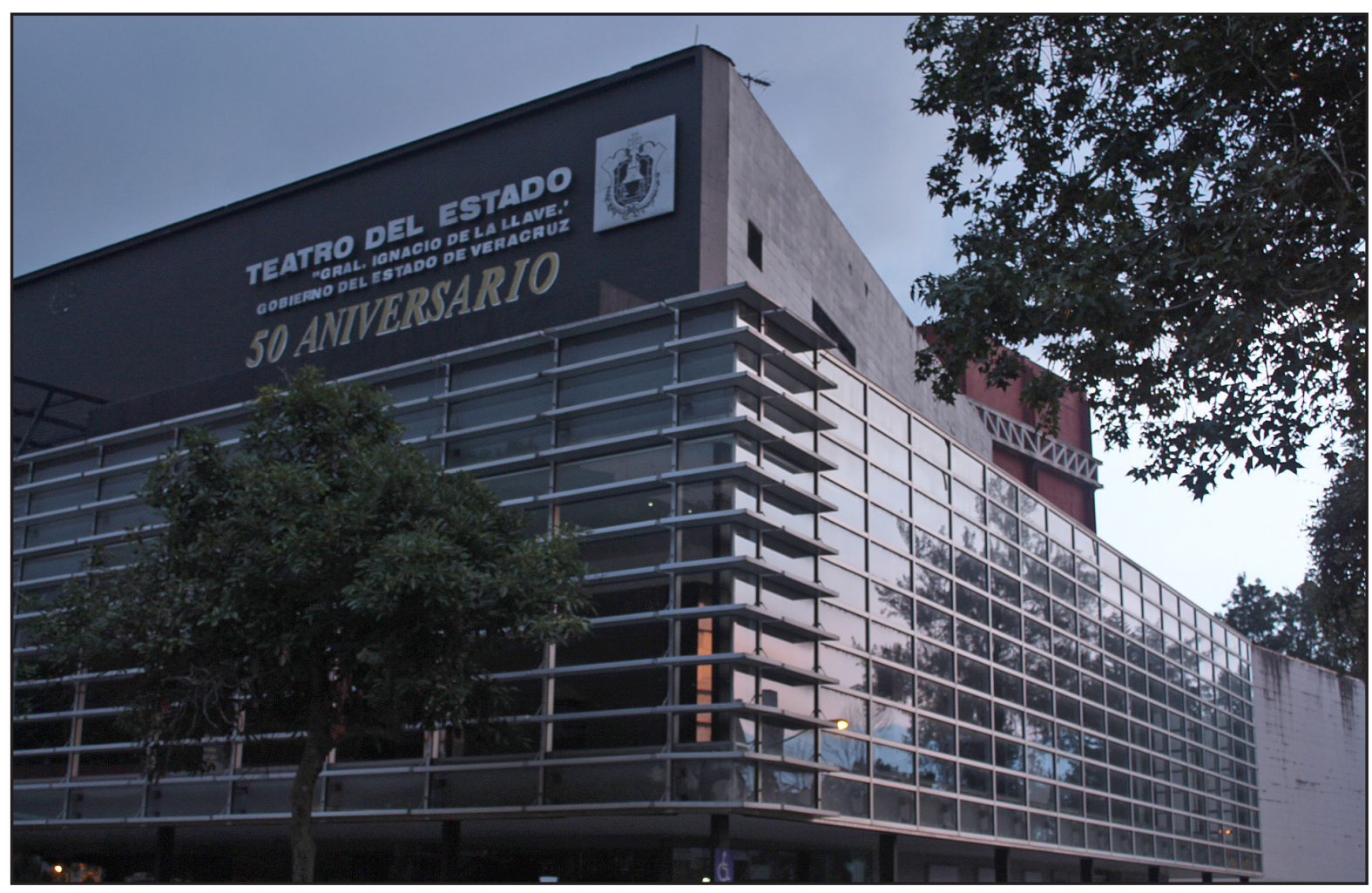

Teatro del Estado “Gral. Ignacio de la Llave”. Xalapa, 2019. Fotografía de José Luis Gómez Córdova.

Este estudio surge de la revisión del archivo documental resultante de las diez publicaciones anuales de Teatro en los estados, ${ }^{1}$ es decir, parte de las ciencias de la información en estrecha cercanía con el periodismo que, de acuerdo con López Yepes, tienen una afinidad natural. Sobre la documentación, entre otras características, López Yepes menciona que se trata de la "obtención de información para la acertada toma de decisiones" ("La información" 15’37”) y entiende la información como un bien social en estrecha relación con el poder ("El concepto" 6). Es en este vértice que localizo mi trabajo y su importancia.

Gracias al trabajo de documentación realizado para la serie Teatro en los estados, he podido observar la actividad teatral de los estados año con año en relación con su tamaño y el de su población, siendo Xalapa la única ciudad de menos de 500 mil habitantes con una intensa actividad teatral. Este estudio parte de la hipótesis de que Xalapa es la ciudad con mayor actividad teatral en el país.

1 Teatro en los estados es un registro documental anual de las obras presentadas fuera de la Ciudad de México, realizado por quien suscribe. 
En la primera parte del artículo se procura otorgar, al lector, los postulados ideológicos de los cuales parto para hacer la investigación. Me enfoco en la relación del modelo económico neoliberal con la tendencia homogeneizadora hacia los artistas que genera un problema político respecto a la diversidad cultural, lo cual, a la vez, se incrementa con la tendencia centralista del sistema político mexicano.

En el segundo apartado se comparten algunas de las conclusiones del proyecto Teatro en los estados para otorgar un panorama sobre la actividad teatral en México, con la finalidad de tener un contexto general que permita enfocarnos, en la tercera parte, en el caso de Xalapa.

En cuanto a la metodología, se utiliza una serie de siete años para generar los promedios anuales de obras presentadas que se muestran en el estudio, salvo la comparativa correspondiente a la Ciudad de México. Esta última se realizó sobre el 2013 como año base, debido a que no se cuenta con datos equiparables relativos a la Ciudad de México durante esos siete años.

\subsection{Marco teórico}

\subsubsection{Diversidad cultural}

En los años setenta, la UNESCO publicó sus primeras monografías sobre políticas culturales nacionales; en 2001 realizó la Declaración Universal de la UNESCo sobre la Diversidad Cultural, y en 2005, la Convención sobre la Protección y la Promoción de la Diversidad de las Expresiones Culturales, de la cual México forma parte y fue electo miembro del Comité Intergubernamental para el periodo 2007-2011.

Una de las principales razones por las que la UNESCO consideró necesaria la creación de la Convención fue que:

La producción, distribución, exhibición y promoción cultural a nivel mundial está cada vez más monopolizada; menos propietarios que nunca antes dominan el mercado cultural. Al mismo tiempo, las opciones disponibles para los consumidores en muchos ámbitos de las artes están menos diversificadas. La vida cultural se restringe cuando la variedad de expresiones artísticas que pueden llegar a públicos y consumidores de obras de arte se ve reducida. Desde una perspectiva de derechos humanos, éste no es un desarrollo saludable. Esta reducción en el número de propietarios y en la diversidad de opciones supone también una amenaza para la democracia, puesto que una rica diversidad de voces e imágenes es fundamental para el discurso democrático (Pulido, et al 7). 
En México, el modelo económico neoliberal y el centralismo en el sistema político han favorecido este panorama, promoviendo la discriminación y marginación económica de creadores que radican fuera de la Ciudad de México. De acuerdo con Jaime Fisher, esto convierte a la diversidad cultural en un problema político. ${ }^{2}$

La diversidad cultural es un tema amplio y con muchas discusiones actuales que no abordaremos aquí. Sin embargo, para contextualizar la relevancia simbólica del estudio que presento, recordaré el caso de la $35^{\mathrm{a}}$ Muestra Nacional de Teatro (Monterrey, Nuevo León 2014), donde la programación estuvo compuesta por un $54 \%$ de obras provenientes de la Ciudad de México, el porcentaje más alto registrado en una comparativa de la programación de la MNT desde el 2008 (Serrano, "Por un nuevo modelo").

Esta situación desató una discusión que resultó en una revisión y adecuación del modelo para la siguiente edición, en 2015. Quiero tomar sólo un fragmento de esta discusión para dimensionar el problema de la diversidad cultural. A raíz de los diferentes reclamos, el dramaturgo y director teatral David Gaitán escribió una nota en Teatromexicano.com en respuesta:

Reclamar que haya más obras de los estados apelando a las estadísticas de la selección es exigir que se reparta el presupuesto equitativamente entre los colegas (como si fuéramos los únicos que pagamos los impuestos que permiten que este evento se lleve a cabo) y olvidar que el criterio más importante, en tanto que compete al espectador, es la calidad artística; no la dirección postal del teatro en que se estrenó ("Que si del DF”).

Gaitán no era el único que pensaba de esta manera. En el medio teatral es muy común que se hable de "calidad" como criterio estético, como también que se haga una distinción entre espectadores y gente de teatro. ${ }^{3}$ En contraparte, concuerdo con la idea de que cada expresión artística, ya sea amateur o profesional, tiene importancia en tanto que pone el arte en el contexto de su cultura y su sociedad ${ }^{4}$ a la manera en que Geertz lo refiere:

2 Un problema político auténtico surgiría cuando de la diversidad cultural de facto emerge la intolerancia, la "discriminación, la exclusión política o la marginación económica, es decir, algún tipo de violencia física o simbólica” (Fisher 41).

3 "La lucha por mejorar las posibilidades de profesionalización artística en los distintos estados del país es una que debe hacerse, pero atacar la programación de la MNT bajo el criterio comentado es arremeter contra el síntoma. Lo bueno, tampoco le importan estas discusiones al espectador" ("Que si del DF").

4 "La cultura es resultado, a la vez que condición de la relación dinámica entre el individuo y sociedad, y de ambos con el medio ambiente. Su lugar de manifestación es siempre físico [...] Cultura y sociedad no son cosas separadas pero son conceptos distintos" (Fisher, "Liberalismo" 31-34). 
Toda reflexión sobre el arte que no sea simplemente técnica o bien una mera espiritualización de la técnica ${ }^{5}$-esto es, gran parte de ese debate- pretende básicamente situar el arte en el contexto de esas otras expresiones de la iniciativa humana, y en el modelo de la experiencia que éstas sostienen colectivamente (119).

En el teatro, esta relación es muy inmediata y debería ser considerada en la discusión de las atribuciones y aportaciones artísticas de una obra, por encima de la llamada "calidad". ¿Cuáles son los parámetros para definir la "calidad" de una obra? Esto fue central en la discusión citada, donde se reclamaba que dichos parámetros se establecen desde una visión centralista y homogeneizante.

\subsubsection{El modelo neoliberal y el centralismo en la cultura en México}

Para entender la necesidad de este artículo por demostrar la importancia del teatro en Xalapa, es indispensable hablar del modelo económico neoliberal y el centralismo en México. No es la intención aquí explicar exhaustivamente estos modelos económicos y políticos, sino simplemente situar desde qué óptica se planea la presente investigación, que si bien está buscando una reivindicación artística lo hace desde una crítica al sistema político y económico que continúa marginando a las expresiones culturales que no se producen desde el centro y que no se perciben como autosustentables.

Con la finalidad de abordar estos temas de manera sencilla y ordenada, nos centraremos en dos artículos que hacen un recuento histórico de estos modelos: "Liberalismo, Neoliberalismo, Postneoliberalismo", de José Guadalupe Vargas Hernández, y "Gobierno y política local en México: luces y sombras de las reformas descentralizadoras", de Enrique Cabrero Mendoza. Ambos artículos tienen una perspectiva histórica y crítica con la que comulgo.

Capitalismo, neoliberalismo y centralismo han caminado de la mano en el sistema político y económico mexicano:

El capitalismo que proclama la libertad superó las injustas relaciones económicas del régimen feudal pero se convirtió en la justificación para el saqueo de los recursos de los pueblos menos desarrollados durante la colonia en beneficio de las metrópolis. La expansión del capitalismo se efectuó a través de la organización de la sociedad, el modo de producción y el poder político en los espacios coloniales. La herencia colonial ha

5 A lo que llamará David Gaitán "la calidad artística". 
marcado las estructuras económicas, políticas, sociales y culturales de los pueblos colonizados. Por lo tanto, la estructura actual del sistema internacional se entiende a partir de la evolución de las características del sistema internacional capitalista.

[...] Las políticas proteccionistas de los denominados mercados emergentes impedían el avance del proyecto del libre mercado, por lo que el neoliberalismo condena y arremete contra la ideología del desarrollo a través de la aplicación de regulaciones de las instituciones financieras internacionales para convertir a las economías emergentes en consumidoras de productos y servicios de los países más avanzados, para quienes estas regulaciones no aplican (Vargas 72, 82).

Por su parte, Cabrero Mendoza explica que el centralismo fue una medida de control que adoptó el gobierno postrevolucionario mexicano y que no fue sino hasta el periodo de 1970-1977 que surgieron las primeras iniciativas descentralizadoras (168). Sin embargo, durante la presidencia de Carlos Salinas (1988-1994), "la descentralización como iniciativa gubernamental prácticamente ${ }^{6}$ desapareció como tema de la agenda de gobierno” (170). Es también en este periodo cuando se aceleraron las medidas económicas neoliberales en México con el Tratado de Libre Comercio en América del Norte (Vargas 84).

Al tiempo que el neoliberalismo "alienta como medidas económicas la reducción del gasto público, especialmente la reducción de prestaciones de servicios por parte del Estado, particularmente a los sectores más pobres de la población" (ibídem), los erráticos procesos de descentralización en México han provocado que persistan rezagos básicos en los gobiernos estatales y municipales (Cabrero 174).

A pesar de que a partir de 1994, con el presidente Ernesto Zedillo, se planteó una iniciativa de un "federalismo renovado" -explica Cabrero Mendoza-, fue un proceso de "descentralización impuesta por el poder presidencial" donde los estados y municipios eran "simples receptores de una política centralmente diseñada"; por ello, Cabrero Mendoza afirma que en México no ha existido "una estrategia global y articulada de mediano a largo plazo para la descentralización”, produciendo finalmente un centralismo multiplicado. Al decir de este investigador, "el centralismo en un país como México está instalado en las raíces mismas del sistema social, en el imaginario colectivo que da vida a esta nación y que, por tanto, favorece la reproducción de estos vicios centralizadores" (171, 172, 174, 167).

Por su parte, Vargas Hernández también piensa que se necesita de una revolución cultural que no acepte "las formas de dominación, poder y alineación del capitalismo globalizador para reconstruir la identidad de las comunidades mediante la acción individual y

6 El autor señala como excepción la política educativa en este periodo. 
colectiva que afirme la autodeterminación, independencia y autogestión" (86). Por eso es indispensable insistir en ver hacia fuera del centro, promover mejores condiciones en los estados. El modelo económico neoliberal y las políticas centralistas son esencialmente homogeneizadoras de los discursos y, por lo tanto, atentan contra la diversidad cultural.

\subsection{Estado de la cuestión}

La historia del teatro en Xalapa está ampliamente documentada; sin embargo, se ha centrado principalmente en la actividad alrededor de la Universidad Veracruzana y en especial de la Compañía Titular de Teatro de la Universidad. Los investigadores Elka Fediuk y Francisco Beverido tienen publicados varios artículos al respecto; algunos de ellos fueron utilizados para la realización del libro Compañía Titular de Teatro de la uv: Testimonios de 60 años, el cual está construido con base en entrevistas, notas de prensa y críticas teatrales.

Queda pendiente una historia del teatro independiente en Xalapa que seguramente será posible gracias al Centro de Documentación Teatral Candileja, dirigido por Francisco Beverido, el cual cuenta con un fondo documental bastante amplio. Por otro lado, aunque es necesaria la historia de Xalapa y su teatro para el desarrollo de esta investigación, la presente argumentación se circunscribe a un aspecto estadístico. La serie Teatro en los estados tiene documentadas las obras presentadas del 2007 al 2015, la revisión de ese material será base para el argumento del presente escrito, así como los ensayos publicados en estas ediciones.

La investigación que tiene más relación con lo que busco conseguir en este artículo es la realizada por Nadia Be'er, que aborda problemáticas específicas del teatro y las utiliza como indicadores para revisar la política cultural del sexenio.

En el artículo titulado "Lo que el teatro revela de la política cultural del sexenio", Be'er revisa la distribución geográfica de los apoyos otorgados por el Fondo Nacional para la Cultura y las Artes (Fonca), las actividades realizadas por la Coordinación de Teatro del inBA (entre las que se cuenta la Muestra Nacional de Teatro y otros festivales), los presupuestos asignados a cultura y el Programa Estímulos Fiscales Efiteatro, para concluir lo siguiente: "La simulación de muchos de los programas nos remonta coincidentemente a los orígenes del teatro occidental: en Grecia, a los actores se les denominaban hypokrités. Hoy, en México, el actor es actor, pero la política cultural que lo acompaña es hipócrita" (párrafo 43).

A pesar de que el artículo de Be'er navega entre datos sin terminar de analizarlos ni ofrecer una interpretación específica para cada uno de los casos, son pocos los ejemplos de este tipo de estudios. Interesa el planteamiento de su artículo: 
Entre recortes, la fundación de la esperada Secretaría de Cultura y las condiciones laborales de muchos de los trabajadores de la cultura, es difícil hacer un balance del estado en el que este sexenio deja a las artes. En este texto, el teatro funciona como una mirilla para ver algunos de los esfuerzos, dinámicas y puntos ciegos en nuestra política artística y cultural que, sin embargo, no sólo depende de presidentes y gabinetes, sino de una serie de agentes y acciones que urge repensar si queremos una sociedad educada en las artes, teatros llenos y creadores bien pagados (párrafo 1).

Finalmente, lo que se pretende con este artículo es otorgar argumentos que demuestren que no toda la actividad cultural se concentra en la Ciudad de México y que es posible pensar en una política cultural descentralizada.

\section{Actividad teatral profesional en México}

¿Cómo definimos el teatro profesional? La formación de quienes participan en el montaje y los medios de producción de la puesta en escena son elementos que proponen cierta objetividad al responder esta pregunta. Sin embargo, sólo estaríamos contemplando la parte técnica. De acuerdo con Geertz, "estudiar una forma de arte significa explorar una sensibilidad, que una sensibilidad semejante es esencialmente una formación colectiva y que los fundamentos de esa formación son tan amplios y profundos como la existencia social" (122). Cuando hablamos del teatro que se produce fuera de la capital de México, en muchos casos, las figuras reconocidas del teatro no tienen una formación profesional y la mayoría de los recursos para la producción son independientes, es decir, provistos por los propios creadores. El crítico Fernando de Ita escribió al respecto:

[...] hace 30 años el teatro en provincia era un teatro de aficionados, en el mejor sentido de la palabra. Sólo las ciudades de México, Puebla, Monterrey y Xalapa contaban con escuelas formales para la enseñanza del arte dramático, o con profesionales de las tablas que continuaban la tradición de formar gente de teatro sobre la marcha.

Desde los años 60 los directores se convirtieron en los personajes centrales de la convocatoria que es necesario hacer para montar una obra de teatro, fuera del circuito comercial. El teatro subsidiado permitió, en la ciudad de México, la experimentación artística que llevó a un puñado de creadores a dominar el escenario, tanto en el aspecto de apoyo y producción, como en el sentido artístico. Ante la ausencia de pedagogos, y del personal adecuado para la administración de la cultura, quienes dirigían las obras del teatro público se convirtieron en maestros, funcionarios y promotores de teatro. 
Lo mismo pasó en los estados, con la salvedad de que en el rancho no había dinero para la cultura, menos para el teatro. Los directores en provincia también reinaban sobre sus alumnos, pero no les podían ofrecer los sueldos mínimos que paga el teatro trashumante en el Distrito Federal, por ejemplo. Tampoco los podían compensar con una temporada fija, ni con la sala llena de espectadores, ni el halago de la prensa, porque muchas veces las obras sólo se daban la noche de estreno, no había público, y no había espacio para ellos en los diarios. Por eso digo que en diversos estados había una afición ejemplar por el teatro, pues con todo en contra, montaban obras de teatro (9).

Necesitamos considerar muchos otros elementos; sin embargo, es tan amplia y diversa la actividad teatral en el país que sería imposible generar una definición homóloga. Por lo tanto, Teatro en los estados ha trabajado en proponer la generación de criterios que consideren esa diversidad para trazar un mapa y ofrecer coordenadas posibles de navegación. Los anuarios resultantes de este proyecto siempre se pensaron como una documentación que sirviera para futuras investigaciones. Los criterios iniciales ${ }^{7}$ han tenido que ser revisados en varias ocasiones para tomar en cuenta factores que no se consideraban; por ejemplo, la complejidad geopolítica de la zona de La Laguna. La llamada Comarca Lagunera se ubica en los estados de Coahuila y Durango y funciona como una entidad aparte, lo que hace imposible determinar si las obras producidas en esa zona son de Durango o de Coahuila, por lo cual se señalan aparte bajo el nombre de Comarca Lagunera. ${ }^{8}$

Volvamos ahora a la pregunta: ¿qué es el teatro profesional? El Diccionario de la Real Academia Española define "profesional" como lo relativo a la profesión, aquel oficio por el que se percibe una retribución. La forma directa de percibir una retribución en el teatro es la taquilla, que fue el primer criterio establecido en la primera edición. Pero, conociendo el campo de primera mano, sabía que existen otras maneras de obtener ingresos para una obra de teatro sin pasar por la taquilla (como las becas, los apoyos institucionales y la venta

7 "Este anuario está dedicado a los trabajos de teatro profesionales de todo el interior de la República Mexicana. Profesional es un término escurridizo, por lo que se definió del siguiente modo: todo aquel que cobre taquilla. También se incluyeron dentro del anuario toda obra que haya participado en algún festival, encuentro, concurso, feria o festejo público. De este modo se incluyen en el anuario obras estudiantiles, de niños o didácticas que de alguna manera lograron sobrepasar su ámbito inmediato y formar parte de la actividad teatral de su localidad. En el caso de teatro de calle, resulta muy difícil rastrear las obras y diferenciarlas como un producto artístico, por lo que únicamente se incluyen las obras que pudieron ser cotejadas en un medio periodístico, cartelera cultural o festival de teatro" (Serrano, Teatro en los estados 2007 7).

8 Se crea el apartado de Comarca Lagunera a partir de la edición 2009 (Serrano, Teatro en los estados 2009 8). 
de funciones). De ese modo, quedaron establecidos los siguientes criterios para registrar una obra en los anuarios:

- Que haya cobrado taquilla.

- Que haya participado en algún festival.

- Que haya contado con algún apoyo de cualquier orden de gobierno.

- Que haya participado dentro de algún programa de cualquier orden de gobierno.

Los anuarios registran todo aquello que se autonombre como teatro, ya sea teatro-circo, teatro-danza, danza-teatro, teatro testimonial, teatro expandido. El propósito de tal registro no es establecer las fronteras del teatro, son los propios creadores quienes se asumen dentro o en diálogo con dicha disciplina. El origen de la obra se establece a partir de los recursos de la producción, ya que uno de los propósitos del registro es poder dar seguimiento a la inversión que hace cada estado en teatro. Por ejemplo, si la obra cuenta con un reparto integrado por actores de la Ciudad de México bajo la dirección de una persona que nació en Veracruz, aunque radica y labora en Mérida, pero la producción se realizó con un apoyo del estado de Chihuahua, la obra se verá reflejada en la sección de Chihuahua.

Para la edición de 2014, contando ya con el material de ocho años, se podían observar algunas imprecisiones en la metodología: ${ }^{9}$ la tendencia general al alza de la actividad teatral en los estados, ${ }^{10}$ en contraste con la corta vida de las obras. Por lo tanto, establecimos un nuevo indicador llamado Actividad profesional, el cual se compone con la suma de las reposiciones de un año más las del año siguiente. Esa suma da un estimado de la producción teatral profesional, una proyección no exacta pero razonable y acorde con las características de la actividad. De hecho, es una cifra mucho más precisa que un promedio anual, por ejemplo.

Es decir, para determinar una obra dentro de la Actividad teatral profesional, además de haber tenido una temporada con taquilla comprobable o haber participado en algún festival o contado con apoyo institucional, debe haber tenido funciones comprobables en diferentes años, no necesariamente consecutivos. La vida útil de una puesta en escena es un factor importante para considerar una obra como profesional en términos de productividad económica. Al aplicar este criterio, como se puede ver en la tabla siguiente, el número de obras consideradas como Actividad teatral profesional se reduce considerablemente, en promedio un $40 \%$ :

9 "En algunos estados como Chiapas, Tabasco, Tlaxcala, Durango o Zacatecas es muy difícil corroborar el cobro de taquilla, no hay suficiente información sobre las obras" (Serrano, Teatro en los estados 2014 7)

10 En 2014 se presentaron 95\% más obras que en 2007 (ibídem). 


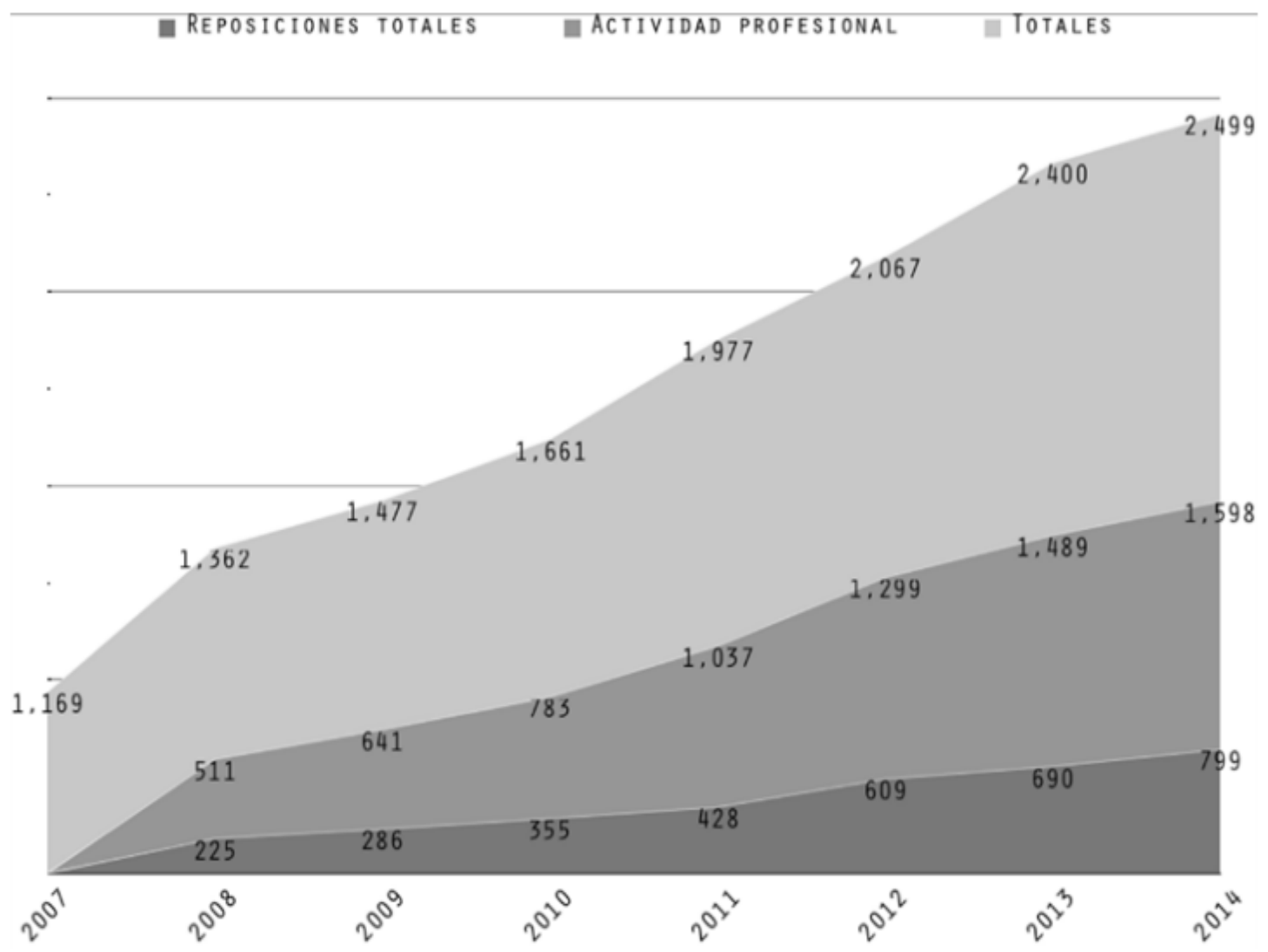

Tabla de Teatro en los Estados 2014, página 11.

A pesar de la reducción, más de 1,500 obras profesionales en los estados es un número bastante alto, sobre todo considerando que se triplicó en cinco años. Sin embargo, a pesar de esta efervescencia teatral en los estados, la realidad cotidiana es muy distinta a la de la Ciudad de México, donde se concentra la mayor parte de los apoyos gubernamentales ${ }^{11}$ y de la iniciativa privada. El problema se agrava por la falta de información que existe sobre lo que sucede en los estados y la poca vigilancia de los actores sociales sobre los bienes y políticas culturales en la mayoría de las entidades federativas, por lo que proponer un mecanismo para el diagnóstico local y generar un panorama nacional

11 Al respecto, conviene revisar a detalle el artículo de Nadia Be'er: "Lo que el teatro revela de la política cultural del sexenio". 
diferenciado aportaría herramientas para la creación de políticas locales de desarrollo sostenible (Cabrero/Serrano, Teatro en los estados 2007-2017).

Aplicando este último criterio a la información recopilada a lo largo de ocho años (2007-2014), de un total de 11,322 obras registradas en este periodo, sólo 3,049 han tenido presentaciones después del año de su estreno, es decir, solamente el 27\% de la producción de teatro fuera de la Ciudad de México puede ser considerada como profesional. Aquí hay que distinguir entre "producción" (la cantidad de obras que se realizan) y "actividad teatral" (la relación de la cantidad de obras que se presentan con un tiempo y un espacio determinado).

A finales de la segunda década del siglo xxi, ya podemos hablar de cuatro capitales teatrales en los estados que cuentan con una actividad profesional sólida, constante y que impacta de manera regional: Guadalajara, Xalapa, Monterrey y Mérida (ibídem).

\section{Xalapa, capital teatral}

\subsection{Contexto}

La capital veracruzana es una ciudad particular. Sus habitantes llevan con orgullo su sobrenombre: "La Atenas veracruzana". Gracias a la Universidad Veracruzana, la actividad artística y cultural es parte de la identidad de Xalapa. La tradición editorial, musical y teatral tiene un peso importante. La editorial de la UV, con más de 70 años de trayectoria, fue la primera en publicar a Gabriel García Márquez; la Orquesta Sinfónica de Xalapa, fundada en 1929, ha forjado y continúa con una sólida trayectoria, al igual que la Compañía Titular de Teatro que, con más de 70 años, es la compañía más longeva del país. En suma, Xalapa -vía la Universidad Veracruzana - ha sido pionera en el ámbito artístico cultural y una capital teatral fuera de la Ciudad de México (Serrano, Compañía Titular).

Una ciudad así nos obliga a replantear el tema de qué es importante registrar en cuanto a actividad teatral. La actividad que podemos llamar profesional bajo estrictos criterios es muy reducida: de las 712 obras registradas entre 2007 y 2014, sólo 190 cumplen los criterios antes establecidos. ${ }^{12}$

Si observamos la historia de la Compañía Titular de Teatro de la Universidad Veracruzana, encontraremos que se oficializó como tal y con un presupuesto asignado hasta mediados de los setenta y que inició en 1953 como un taller de teatro amateur. No todo el teatro amateur

12 El 26.7\%, prácticamente el mismo porcentaje de actividad teatral profesional que el total nacional de $27 \%$. 
llega a impactar a la escena profesional, pero en esto no radica su importancia, sino en la construcción propia de conocimiento, de relaciones en su comunidad, como se puede intuir en los postulados de Geertz en su libro El conocimiento local (quien no menciona específicamente al teatro, pero sí las formas de conocimiento local y el arte como un sistema de pensamiento). Geertz también señala continuamente en ese libro la subestimación que ha tenido el pensamiento no hegemónico, como también lo hacía Peter Burke en su Historia social del conocimiento. ¿Cómo valorar, entonces, estas expresiones en su justa dimensión?

La historia de Xalapa se puede contar a través de su teatro, pero no sólo del teatro institucional, esa es nada más una parte. El teatro independiente ha puesto de manifiesto la indolencia de los políticos veracruzanos no sólo hacia las artes, sino en general, con pruebas muy contundentes. Así como Pilar Gonzalbo nos habla de un cambio de perspectiva social en la Colonia al revisar las actas bautismales, es decir, al revisar la historia de la vida cotidiana, podemos estudiar la historia social y política de Xalapa a través del quehacer teatral.

Sobre esto, Patricia Estrada, directora radicada en Xalapa, señala que:

En un momento crítico, de dificultades económicas y sociales, con una violencia creciente en el estado, existieron movimientos artísticos que funcionaron bajo estas condiciones, no sólo para sí mismos sino que formaron un eco hacia el gremio. Uno de estos movimientos fue la creación de espacios, foros independientes que comenzaron a surgir como respuesta de los artistas hacia sus propias necesidades. Como ejemplo, las compañías Febrero 10 y Merequetengue Artes Vivas, quienes a partir del cierre del Centro de Estudios en el Arte de los Títeres (CEAT) en 2009 que dirigía Carlos Converso, nacieron dos nuevos espacios importantes en las búsquedas tanto en el lenguaje de los títeres como en la enseñanza para niños: El Telón, del grupo Febrero 10, y El Rincón de los Títeres, de Merequetengue.

Otros espacios escénicos como Espacio Vacío, El Foro Estudio de Literateatro, Teatro la Libertad y Área 51 nos demuestran que aunque las condiciones son adversas la sociedad civil lucha por crear condiciones propicias de trabajo y, a pesar de todo, en fechas recientes nuevos espacios independientes abrieron sus puertas: Casa 13, Foro El Búnker, Obra Negra.

Pregunté a algunos compañeros cuál era su diagnóstico sobre los últimos diez años del quehacer teatral en el estado, porque me parecía difícil plantear algo que se alejara a lo que ya se había dicho antes. En todos los casos la respuesta fue la misma: ¿En qué momento decidimos vivir con la idea de la resistencia y el abandono? (“Xalapa” 14).

Otra característica de Xalapa es que es tierra de paso; sobre este tema ahondé en un ensayo para el anuario de 2009: 
INVESTIGACIÓNTEATRAL

Revista de artes escénicas y performatividad

Vol. 10, Núm. 16

octubre 2019-marzo 2020
Xalapa, capital teatral de México

Alejandra Serrano Rodríguez

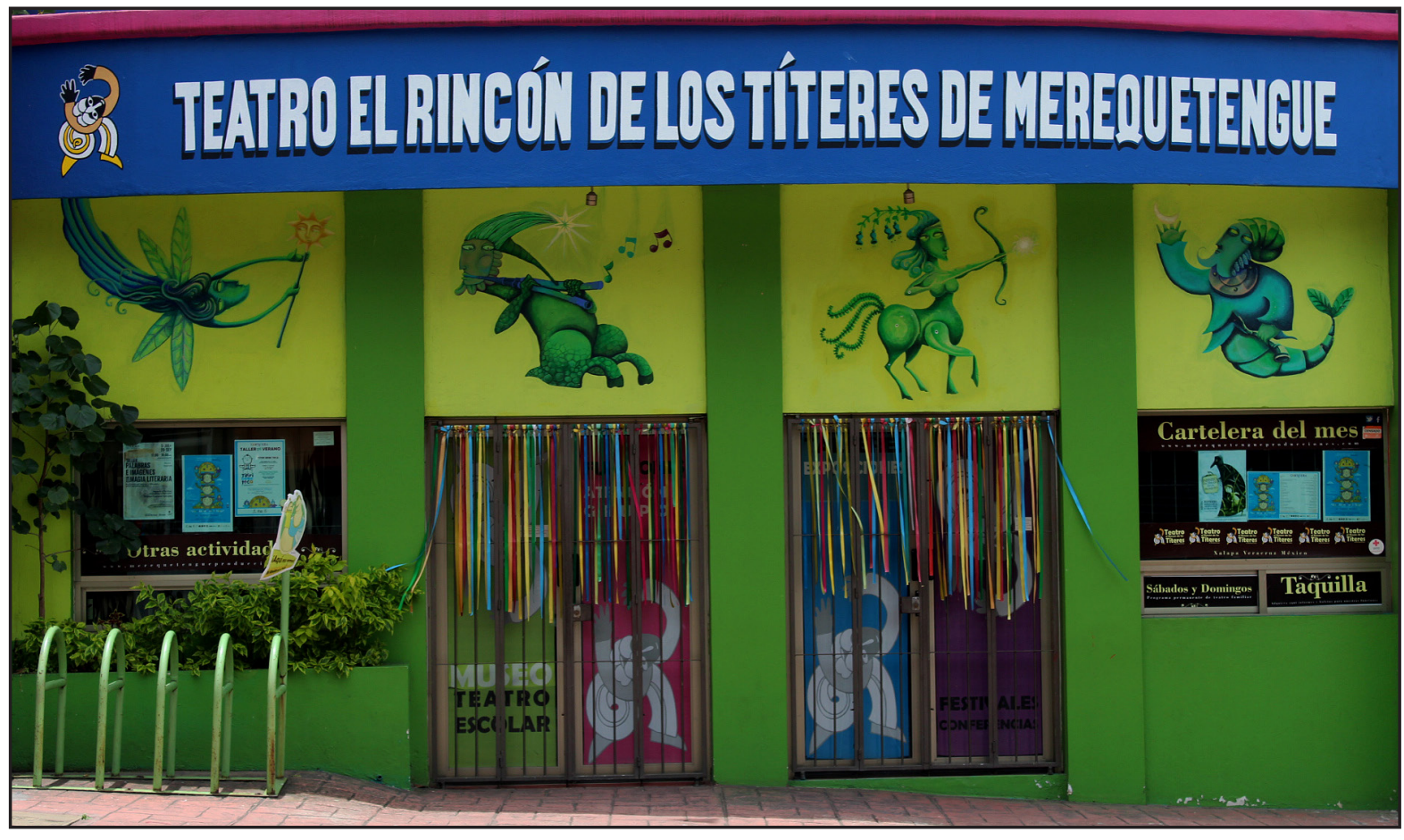

El Rincón de los Títeres de Merequetengue. Xalapa, 2019. Fotografía de José Luis Gómez Córdova.

Cada año llegan a Xalapa jóvenes de todo el país, y alguno que otro del extranjero, para estudiar la licenciatura en teatro, no todos ellos terminarán la carrera y quienes la terminen -siendo de Xalapa o no- buscarán suerte en otras latitudes. Xalapa es tierra de paso. En los últimos años, varios de estos jóvenes han apostado por Xalapa y han permanecido en la ciudad, dando continuidad al trabajo. Este hecho permitió que se diera un caso como Más pequeños que el Guggenheim (escrita y dirigida por Alejandro Ricaño, 2009), obra que fue de las mejores puestas en escena del año a nivel nacional, y con el mérito de ser una producción independiente en todo sentido (Anuario digital).

Al paso de los años, Xalapa les quedó chica a todos los integrantes de Más pequeños que el Guggenheim, aunque mantienen lazos y proyectos en la ciudad. El CEAT, por otro lado, nunca reabrió, pero el Rincón de los Títeres cobró fuerza y en 2013 abrió un nuevo espacio construido desde los cimientos, uno de los foros más activos de la ciudad, cuya construcción estuvo auspiciada por el Gobierno Municipal de Xalapa.

También en 2013 abrió sus puertas el foro Área 51, primero en tener el apoyo del Programa México en Escena del Fonca en Veracruz. Aunque irse a la Ciudad de México o 
INVESTIGACIÓNTEATRAL

Revista de artes escénicas y performatividad

Vol. 10, Núm. 16

octubre 2019-marzo 2020
Xalapa, capital teatral de México

Alejandra Serrano Rodríguez

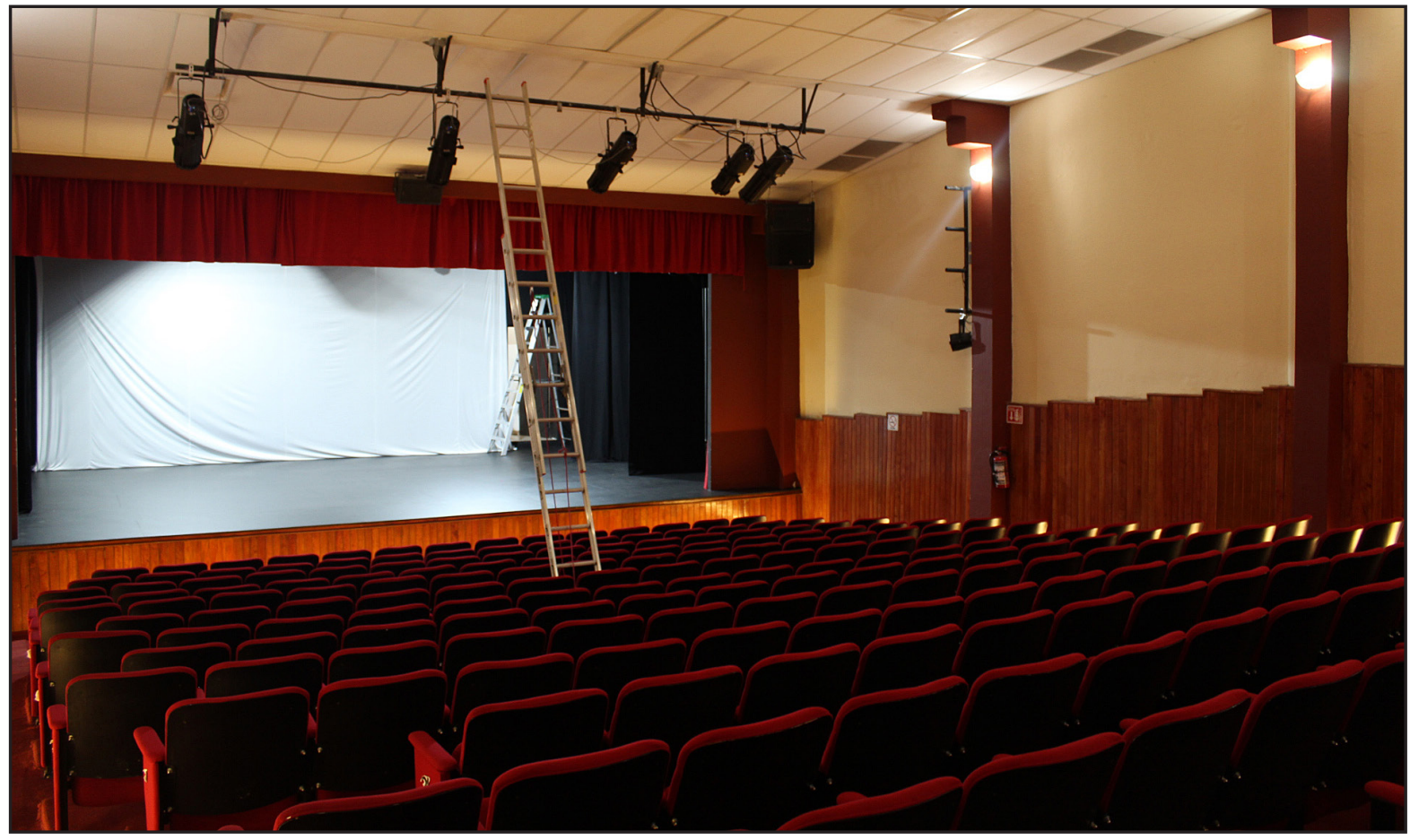

Interior del Teatro J. J. Herrera. Xalapa, 2019. Fotografía de José Luis Gómez Córdova.

regresar a sus lugares de origen sigue siendo la tendencia y la principal aspiración de los egresados de la Facultad de Teatro de la uv, ya hay resultados concretos de gente que se ha quedado a trabajar para intentar mejorar las condiciones para la cultura en Veracruz.

De acuerdo con una investigación de campo que realicé a principios de 2018 con base en las carteleras de la ciudad, los espacios institucionales en Xalapa y sus perfiles son:

1. Sala Tajín (DIF): No programa, se renta. No tiene programación constante. No está en buenas condiciones, no tiene equipo.

2. Centro Recreativo Xalapeño (Ayuntamiento de Xalapa): Abierto a todo tipo de expresiones, programación irregular.

3. Teatro J.J. Herrera (Ayuntamiento de Xalapa): Abierto a todo tipo de expresiones, programación irregular.

4. Auditorio del imac (Ayuntamiento de Xalapa): No cuenta con programación, no está en buenas condiciones, no tiene equipo.

5. Ágora (Instituto Veracruzano de la Cultura): No cuenta con buen equipo de iluminación; programan principalmente cine, muy eventualmente otras actividades. 
6. Teatro del Estado (Instituto Veracruzano de la Cultura): Principalmente se presentan las obras de la Compañía Titular de Teatro de la UV; han hecho esfuerzos por programar funciones de grupos independientes de manera esporádica.

7. Casa del Lago (Uv): Programación constante de grupos independientes universitarios.

8. Torre Lapham (Facultad de Teatro Uv): Programación esporádica de los montajes resultantes de la Licenciatura en Teatro.

9. La Caja (Uv): Programación constante de grupos independientes universitarios, algunas producciones de la Compañía Titular de Teatro de la UV y teatro amateur resultado de los Talleres Libres de Teatro de la uv.

Los espacios independientes y sus características son:

1. Área 51 Foro Teatral: Teatro contemporáneo, programación constante, talleres, festivales y varias actividades.

2. El Telón: Teatro para niños y adolescentes. Principalmente ofrecen talleres y cursos. Temporadas esporádicas.

3. Rincón de los Títeres: Teatro de títeres para toda la familia, programación constante, talleres, festivales y varias actividades.

4. El Bunker: Espacio de ensayos del grupo residente. Principalmente ofrecen talleres y cursos. Temporadas esporádicas.

5. Espacio Vacío: Espacio de ensayos del grupo residente. Temporadas esporádicas.

6. Casa 13: Espacio de ensayos del grupo residente. Temporadas esporádicas.

7. Obra Negra: Espacio de ensayos del grupo residente. Temporadas esporádicas. Único grupo de cabaret con espacio propio en la ciudad (Regordet Cabaret).

8. Café Teatro Tierra Luna: Abierto a todo tipo de expresiones, programación irregular.

A inicios de 2018 cerró el Teatro La Libertad, de Abraham Oceransky, otra iniciativa independiente y representativa de la ciudad. Con ella sumaban nueve espacios con estas características a principios de 2018.

\subsection{Comparativa con otras ciudades}

Para realizar esta comparativa sólo se trabajará con las denominadas capitales teatrales: Guadalajara, Xalapa, Monterrey y Mérida, además de Querétaro, por ser la siguiente ciudad en cuanto a la cantidad de teatro presentado. 
El promedio anual de obras producidas en Veracruz es de 122 obras, el 85\% de ellas son de Xalapa; Jalisco y Yucatán guardan una proporción similar con su capital, en tanto que Querétaro y Nuevo León concentran toda la actividad teatral en su capital.

En la siguiente tabla se puede observar la relación entre el número total de obras producidas al año y las que podemos considerar como actividad profesional bajo los criterios antes establecidos:

\begin{tabular}{lccc}
\hline Estado & $\begin{array}{c}\text { Promedio anual } \\
\text { total de obras }\end{array}$ & $\begin{array}{c}\text { Promedio anual de } \\
\text { obras profesionales }\end{array}$ & $\begin{array}{c}\text { \% de actividad } \\
\text { profesional }\end{array}$ \\
\hline Jalisco & 186.7 & $\mathbf{8 8 . 8}$ & $47.6 \%$ \\
\hline Veracruz & 126 & 57.8 & $45.9 \%$ \\
\hline Yucatán & 124.1 & 58.4 & $47 \%$ \\
\hline Querétaro & 110.2 & 53.3 & $48.3 \%$ \\
\hline Nuevo León & 109.8 & 50.8 & $46.3 \%$ \\
\hline
\end{tabular}

Para establecer la actividad teatral se consideró la cantidad de población que existe en cada ciudad, tomando como base el año 2013, ya que a partir de esa fecha se cuentan con los datos completos de todas las entidades. Se consideró también que, aunque la cantidad de obras de teatro es diferente cada año -como se puede observar en la tabla del apartado anterior-, la tendencia a partir del 2012 es un movimiento muy estable:

\begin{tabular}{|c|c|c|c|}
\hline Ciudad & Total de obras 2013 & No. de habitantes ${ }^{13}$ & Relación teatro/habitantes \\
\hline CDMX & $592^{14}$ & $8918653^{15}$ & 1 obra x 15,065.3 hab \\
\hline Guadalajara & 199 & 1460148 & 1 obra $\times 7,337.4$ hab \\
\hline Mérida & 151 & 892363 & 1 obra $\times 5,909.7$ hab \\
\hline Monterrey & 144 & 1109171 & 1 obra $\times$ 7,702.6 hab \\
\hline Querétaro & 121 & 878931 & 1 obra x 7,263.9 hab \\
\hline Xalapa & 105 & 480841 & 1 obra x 4,579.4 hab \\
\hline
\end{tabular}

13 Fuente: INEGI (dato actualizado al 2015).

14 Información proporcionada por el CITRU para Teatro en los Estados 2013.

15 Sin considerar el área conurbada. 
Podríamos decir, entonces, que en 2013 las ciudades con mayor actividad teatral en México fueron:

1. Xalapa

2. Mérida

3. Querétaro

4. Guadalajara

5. Monterrey

6. Ciudad de México

Existen diferencias metodológicas importantes entre la manera de registrar los datos de Teatro en los Estados y la del Anuario teatral del CITRu. La principal diferencia es que Teatro en los estados sólo registra las obras producidas en la entidad correspondiente, de modo que quedan fuera todas las obras en gira y festivales que se presentan en las ciudades. Este dato no forma parte de la actividad teatral del estado en esta metodología.

En cambio, en el Anuario teatral del CITRU (2018) no hay esta distinción, registra todo lo presentado en la Ciudad de México, incluyendo puestas en escena en temporada y otros eventos (ciclos, coloquios, encuentros, festivales, muestras, etcétera). Por lo tanto, se puede asumir que, si buscáramos homologar la información, la cantidad de obras de la Ciudad de México disminuiría (aunque no tanto como para afectar los resultados generales). Para tener mayor precisión sobre la actividad teatral de la ciudad, realicé el mismo ejercicio, utilizando esta vez solamente los números señalados como actividad profesional en 2013, considerando que el CITRU se limita a registrar la actividad en general:

\begin{tabular}{llccc}
\hline Posición & \multicolumn{1}{c}{ Ciudad } & Obras 2013 & No. de habitantes ${ }^{\mathbf{1 6}}$ & Relación teatro/habitantes \\
\hline $1^{\circ}$ & Xalapa & $\mathbf{7 5}$ & 480841 & 1 obra x 6,411.2 hab \\
\hline $2^{\circ}$ & Mérida & $\mathbf{9 0}$ & 892363 & 1 obra x 10,376.3 hab \\
\hline $3^{\circ}$ & Querétaro & $\mathbf{7 1}$ & 878931 & 1 obra x 12,379.3hab \\
\hline $4^{\circ}$ & Guadalajara & $\mathbf{1 0 5}$ & 1460148 & 1 obra x 13,906.2 hab \\
\hline $5^{\circ}$ & CDMX & $\mathbf{5 9 2}$ & $8918653^{17}$ & 1 obra x 15,065.3 hab \\
\hline $6^{\circ}$ & Monterrey & $\mathbf{8 6}$ & 1109171 & 1 obra x 15,622.1 hab \\
\hline
\end{tabular}

16 Fuente: INEGI (dato actualizado al 2015).

17 Sin considerar el área conurbada. 
Como se puede observar, el resultado en la tabla es prácticamente igual, salvo que en esta ocasión la Ciudad de México queda por encima de Monterrey y ya no se observa una distancia tan grande entre la capital y el resto de las ciudades.

Otra forma de medir el movimiento teatral de la ciudad puede ser con relación a sus espacios teatrales independientes. Actualmente, en la Ciudad de México hay 15 espacios independientes: $:^{18}$

\begin{tabular}{|c|c|c|c|}
\hline Ciudad & $\begin{array}{c}\text { Espacios } \\
\text { independientes }\end{array}$ & $\begin{array}{c}\text { Relación teatros/ } \\
\text { territorio }\end{array}$ & $\begin{array}{l}\text { Relación teatros/ } \\
\text { habitantes }\end{array}$ \\
\hline Xalapa & 8 & 1 cada 15.5 km² $^{2}$ & 1 teatro $\times 60,105$ hab \\
\hline CDMX & 15 & 1 cada 99.6 km² & 1 teatro $\times 594,577$ hab \\
\hline
\end{tabular}

De este modo, utilizando tres formas distintas de cuantificar la actividad teatral, la ciudad de Xalapa ha mostrado un amplio margen sobre el resto de las ciudades.

\section{Conclusiones}

A partir de la información presentada y en relación con la densidad poblacional, podemos afirmar que Xalapa es la ciudad con mayor actividad y movimiento teatral del país; es decir, es la capital teatral del país. Si aceptamos esta afirmación habría que repensar las políticas culturales del estado y las convocatorias federales que continúan acentuando la brecha económica entre las producciones de Xalapa y las de la Ciudad de México, a pesar de que, porcentualmente hablando, la productividad de las obras en Xalapa es mayor. ¿Será que para las autoridades no resulta necesario aportar recursos financieros a quienes han trabajado tan bien sin ellos? (por supuesto que este pensamiento ha sido consecuencia del modelo neoliberal para la cultura). Para febrero de 2019, en ninguna otra ciudad, más que en la capital del país, han coexistido dos compañías teatrales con el apoyo del Programa de México en Escena del Fonca y en Veracruz no ha existido ningún proyecto apoyado por Efiteatro.

El valor artístico del teatro debe dejar de pensarse en relación con la apreciación técnica y debe incluir una reflexión sobre el contexto cultural y social que produce ese teatro; sin una mirada condescendiente, pero que tampoco produzca discriminación.

18 Tomando como referencia la pasada Muestra Nacional de Teatro, realizada por primera vez en la Ciudad de México, donde se llevó a cabo una muestra alternativa en espacios independientes llamada “La Libre" (INBA). 


\section{Fuentes consultadas}

Alcocer, Luis. Anuario de Teatro. Centro de Nacional de Investigación, Documentación e Información Teatral Rodolfo Usigli, CITRU-INBA, 12 de febrero de 2018, www.CITRU. INBA.gob.mx/110-fijos/publicaciones/on-line/553-anuario-de-teatro.html, consultado el 13 de agosto de 2019.

Be’er, Nadia. "Lo que el teatro revela de la política cultural del sexenio". Nexos, Nexos, sociedad, ciencia y literatura S.A. de C.V., 28 de junio de 2018, www.cultura.nexos.com. $\mathrm{mx} / \mathrm{p}=16237$, consultado el 13 de agosto de 2019.

Cabrero Mendoza, Enrique. “Gobierno y política local en México: luces y sombras de las reformas descentralizadoras”. Política y Sociedad, núm. 47, 2010, pp. 165-186.

De Ita, Fernando. "Otra vuelta de tuerca”. Teatro en los estados 2007. Xalapa: Altheia ediciones/Ichicult/IQCA/Conarte/IVEC/sCJ, 2008, pp. 9-10.

Estrada, Patricia. Teatro en los estados 2011. Ciudad de México: Citru/Conarte/FIDEIMss/ ICBC/Ichicult/INBA/Libros Malaletra/scJ/sCAO/IQCA/ITCA/ITC/Teatromexicano, 2012.

Estrada, Patricia. "Xalapa: Crisis de pensamiento". Teatro en los estados 2007-2017. Xalapa: CITRU/Fonca/Teatromexicano, 2018, p. 44.

Fisher, Jaime. "Liberalismo, comunitarismo, cultura y multiculturalismo”. Factótum, revista de filosofía, núm. 12, 2014, pp. 29-46, www.revistafactotum.com/revista/f_12/articulos/Factotum_12_3_Jaime_Fisher.pdf, consultado el 13 de agosto de 2019.

Gaitán, David. "Que si del DF... Que si no". Teatromexicano, CITRU-INBA, 10 de noviembre de 2018, www.teatromexicano.com.mx/2929/que-si-del-DF-que-si-no/, consultado el 13 de agosto de 2019.

Geertz, Clifford. Conocimiento local. Ensayos sobre la interpretación de las culturas. Barcelona: Paidós Básica, 1983.

Giménez, Gilberto. "Cultura, identidad y memoria. Materiales para una sociología de los procesos culturales en las franjas fronterizas”. Frontera norte, vol. 21, núm 41, 2009, pp. 7-32, www.scielo.org.mx/scielo.php?script=sci_arttext\&pid=S0187-73722009000100001, consultado el 13 de agosto de 2019.

Gonzalbo, Pilar. "La historia cultural en México". Documentar para investigar, investigar para documentar: la construcción del conocimiento artístico nacional. Ciudad de Méxicó: Secretaría de Cultura/INBA/CITRU, 2017, www.inbadigital.bellasartes.gob.mx:8080/jspui/handle/11271/1456, consultado el 13 de agosto de 2019.

Jarvis, Jeff. El fin de los medios de comunicación de masas. Traducido por Jorge Paredes. Barcelona: Planeta, 2015.

López Yepes, José. "El concepto de la ciencia de la documentación: unidad en la diversidad o diversidad en la unidad”. Investigación Bibliotecológica, archivonomía, bibliotecolo- 
gía e información, vol. 10, núm. 21, 1996, pp. 4-6, rev-ib.unam.mx/ib/index.php/ib/ article/view/3837/3390, consultado el 13 de agosto de 2019.

López Yepes, José. "La información en el origen y desarrollo de la documentación”. YouTube, subido por IIBI UNAM, 18 de noviembre de 2014, www.youtube.com/watch?v=MLK_ $\mathrm{NjAbC \_ c}$, consultado el 13 de agosto de 2019.

Nevarez, Luis, et al. Muestra Nacional de Teatro 1978-2004. Ciudad de México: InBA, 2004. Pulido, José, et al. Re pensar las políticas culturales. México: Unesco, 2016.

Rodríguez Barba, Fabiola. "México y la Convención sobre la protección y la promoción de la diversidad de las expresiones culturales de la unEsco". Foro Internacional, vol. XLVIII, 2008, pp. 861-885, forointernacional.colmex.mx/index.php/fi/issue/view/188/showToc, consultado el 10 de julio de 2018.

Serrano, Alejandra. Teatro en los estados 2007-2017. Ciudad de México: CITRu/Fonca/ Teatromexicano, 2018.

Serrano, Alejandra y Patricia Estrada. Anuario digital, Teatro en los Estados. Teatromexicano, CITRU-INBA, 2018, www.teatromexicano.com.mx/anuario, consultado el 3 de diciembre de 2018.

Serrano, Alejandra. Teatro en los estados 2015. Ciudad de México: CITRu/Conarte/IQCA/Secretaría de Cultura de Michoacán/Secretaría de Cultura de Jalisco/Teatromexicano, 2017.

Serrano, Alejandra. Teatro en los estados 2014. Ciudad de México: Citru/Conarte/InbA/Fonca/IQCA/IVEc/Secretaría de Cultura de Campeche/scj/ Secretaría de Cultura de Oaxaca/Teatromexicano, 2015.

Serrano, Alejandra. Teatro en los Estados 2013. Ciudad de México: CECUT/Citru/Conarte/ INBA/Foncq/IQCA/ISC/ITCA/sCJ/sCAY/Secretaría de Cultura de Oaxaca/Teatromexicano, 2014.

Serrano, Alejandra. "Por un nuevo modelo de Muestra Nacional de Teatro". Teatromexicano, CITRU-INBA, 19 de agosto de 2014, www.teatromexicano.com.mx/7904/por-un-nuevomodelo-de-muestra-nacional-de-teatro, consultado el 10 de noviembre de 2018.

Serrano, Alejandra. Compañía Titular de Teatro de la uv: Testimonios de sesenta años. Xalapa: Editorial uv, 2013.

Serrano, Alejandra. Teatro en los estados 2012. Ciudad de México: CITRu/Conarte/ICED/ INBA/IQCA/ITCA/Libros Malaletra/Secay/Teatromexicano, 2013.

Serrano, Alejandra. Teatro en los estados 2010. Querétaro: INBA/IQCA/Conarte/Ichicult/ Fon$\mathrm{ca} / \mathrm{scJ} /$ Libros Malaletra, 2012.

Serrano, Alejandra. Teatro en los estados 2009. Querétaro: Altheia Ediciones/Secretaría de Cultura de Colima/Espacio Cultural Metro/INBA/ICy/Ichicult/IQC/IzC/Teatro Nazas, 2010 . 
Serrano, Alejandra. Teatro en los estados 2008. Xalapa: Altheia editores/Cecultah/Conarte/ INBA/IQCA/IVEC/IZC/Secretaría de Cultura de Colima, 2009.

Serrano, Alejandra. Teatro en los estados 2007. Xalapa: Altheia ediciones, Ichicult/IQCA, Conarte/IVEC/scJ, 2008.

Vargas Hernández, José Guadalupe. “Liberalismo, Neoliberalismo, Postneoliberalismo”. Revista Mad. Revista del Magíster en Análisis Sistémico Aplicado a la Sociedad, núm. 17, 2007, pp. 66-89, revistamad.uchile.cl/index.php/RMAD/article/view/13938, consultado el 16 de agosto de 2019.

Muestra Nacional de Teatro. Instituto Nacional de Bellas Artes, Coordinación Nacional de Teatro, 2018, www.muestranacionaldeteatro.com.mx, consultado el 12 de diciembre de 2018.

Cuéntame de México. Instituto Nacional de Estadística y Geografía, cuentame.inegi.org.mx, consultado el 2 de diciembre de 2018. 